\title{
Estrogen receptor $\beta$ protects against acoustic trauma in mice
}

\author{
Inna Meltser, ${ }^{1}$ Yeasmin Tahera, ${ }^{1}$ Evan Simpson, ${ }^{2}$ Malou Hultcrantz, ${ }^{3}$ Konstantina Charitidi, ${ }^{1,4}$ \\ Jan-Åke Gustafsson, ${ }^{4}$ and Barbara Canlon ${ }^{1}$

\begin{abstract}
1Department of Physiology and Pharmacology, Karolinska Institutet, Stockholm, Sweden. 2Prince Henry's Institute of Medical Research, Clayton, Victoria, Australia. ${ }^{3}$ Department of Otorhinolaryngology, Karolinska University Hospital, Stockholm, Sweden.

${ }^{4}$ Department of Biosciences and Nutrition, Karolinska Institutet, Huddinge, Sweden.
\end{abstract}

\begin{abstract}
The hormone estradiol affects the auditory system both by itself and by its interaction with neuroprotective factors. In this study, we examined the role of estrogen receptors (ERs) in response to auditory trauma. We found a ligand-dependent protective role for ER $\beta$ in the auditory system by investigating mice deficient in ER $\alpha$ (ERKO mice), ER $\beta$ (BERKO mice), and aromatase (ARKO mice). Basal auditory brainstem response (ABR) thresholds were similar in all animals. An acoustic trauma causing a temporary hearing loss raised ABR thresholds in male and female BERKO and ARKO mice compared with WT and ERKO mice. The ER $\alpha$-selective agonist, propyl(1H) pyrazole-1,3,5-triyl-trisphenol (PPT), partially protected ARKO mice from trauma, while the ER $\beta$-selective agonist, 2,3-bis (4-hydroxyphenyl)-propionitrile (DPN), protected WT and ARKO mice. Immunohistochemistry and western blotting confirmed the expression of ER $\beta$ in cochlea of WT males and females. Levels of brain-derived neurotrophic factor (BDNF), a neuroprotective peptide that can be induced by estrogen, was lower in BERKO and ARKO mice compared with WT. DPN treatment increased BDNF expression in ARKO mice. These data indicate ER $\beta$-mediated neuroprotection involving BDNF in the auditory system of males and females.
\end{abstract}

\section{Introduction}

Both clinical and experimental studies have indicated that estradiol plays a significant role in auditory physiology. Hearing thresholds vary with sex hormone levels during the menstrual cycle (1), postmenopausal women have higher auditory brainstem response (ABR) thresholds than younger women or men $(2,3)$, ovariectomized rats have elevated auditory thresholds compared with intact rats (4), otoacoustic emission amplitudes are larger in females than males (5-8), temporal coding in the auditory nerve improves with estradiol in ovariectomized female fish (9), and hearing disorders are evident in mice and women with Turner syndrome (total or partial loss of one $X$ chromosome) (10). These studies indicate a protective function of estradiol in the female auditory system. Estradiol also has important and distinct physiological roles in males. Aromatase, the enzyme responsible for conversion of testosterone to estradiol, is found throughout the male reproductive system and partakes in spermatogenesis (11-15). Estradiol can also regulate bone formation and cardiovascular tone in elderly males $(16,17)$. Moreover, estradiol maintains cell survival in the central nervous system of males in a manner that is similar to that of females $(18,19)$.

Estradiol acts through estrogen receptors (ERs), which are ligandactivated transcription factors belonging to the nuclear hormone receptor superfamily. The first ER, ER $\alpha$, was cloned in 1986 (20), and the second ER, ER $\beta$, was discovered in 1996 (21). These 2 recep-

Nonstandard abbreviations used: ABR, auditory brainstem response; ARKO, mice deficient in aromatase; BDNF, brain-derived neurotrophic factor; BERKO, mice deficient in ER $\beta$; DPN, 2,3-bis (4-hydroxyphenyl)-propionitrile; ER, estrogen receptor; ERKO, mice deficient in ER $\alpha$ PPT, propyl $(1 \mathrm{H})$ pyrazole-1,3,5-triyl-trisphenol; SPL, sound pressure level.

Conflict of interest: Jan-Åke Gustafsson is a shareholder and consultant for KaroBio $\mathrm{AB}$. All other authors have declared that no conflict of interest exists.

Citation for this article: J. Clin. Invest. 118:1563-1570 (2008). doi:10.1172/JCI32796 tors are the products of 2 distinct genes (22) that are believed to have unique functions in the body (23). They may be simultaneously present in some organs and tissues, whereas in other organs one of the ER types dominates over the other (24-26).

At present there is limited knowledge as to how each estrogen ER type affects the function of the auditory system or whether there are sex-specific facets in the inner ear. Understanding the mechanisms of ER actions in the auditory system is important for improving hormone replacement therapy against hearing loss, especially during aging. In this study, we characterize the effects of ERs on auditory function in male and female mice deficient in aromatase (ARKO mice), ER $\alpha$ (ERKO mice), or ER $\beta$ (BERKO mice). The effect of an acute stress, i.e., acoustic trauma, on ER expression and its modulation of auditory function was determined by pretreatment with specific agonists of each receptor type. The acoustic trauma used in this study results in a temporary auditory threshold shift, a condition that is clinically relevant for industries and other environments where high sound levels produce physical and psychological stress. This acoustic trauma causes excitotoxicity, followed by metabolic disturbances and disruption of the hair cells with auditory neurons. Brain-derived neurotrophic factor (BDNF) protects hair cells and spiral ganglion neurons from damage induced by ototoxic substances and acoustic trauma $(27,28)$. Thus, to further explore the mechanisms underlying ER-mediated protection of hearing, we evaluated the expression of the otoprotective agent BDNF protein in the cochlea of mice lacking ER $\beta$ and aromatase. Interactions between ERs and BDNF are apparent since an estrogen-sensitive response element has been identified in the BDNF gene $(29,30)$.

We report that $\operatorname{ER} \beta$ protects the auditory system against acoustic trauma. These data represent what we believe to be the first experimental evidence directly linking ER expression to the protection of auditory function. 


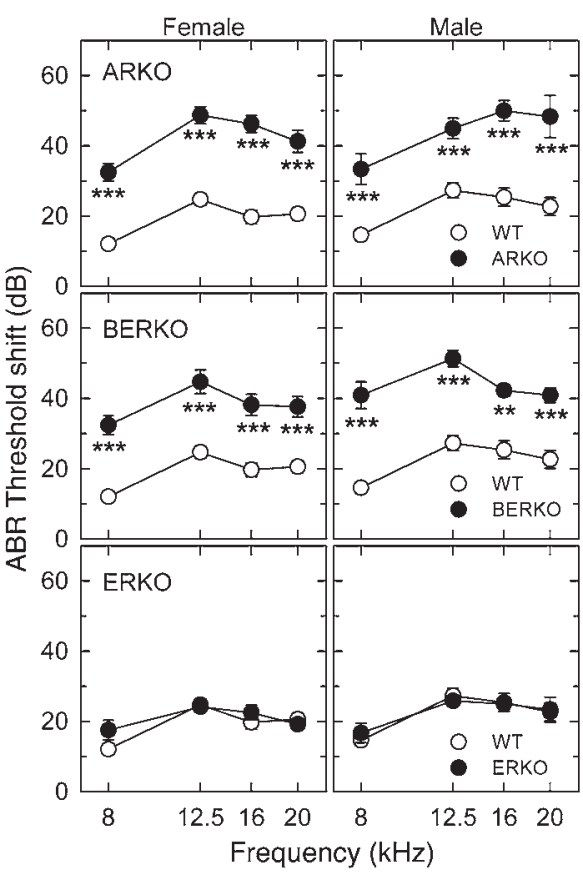

Figure 1

ABR threshold shifts $24 \mathrm{~h}$ after acoustic trauma. The same group of WT male and female mice were used for comparing the different knockout animals. No significant gender difference was observed in threshold shifts. Both female (left) and male (right) ARKO (4 females, 3 males) and BERKO (19 females, 11 males) mice showed significantly elevated threshold shifts at all frequencies compared with sex-matched WT mice (17 females, 13 males). ERKO mice ( 6 females, 6 males) had no differences in threshold shifts compared with WT. All data are means \pm SEM. ${ }^{* \star} P<0.01 ;{ }^{* \star *} P<0.001$ by 2 -way ANOVA.

\section{Results}

$A B R s$. In order to evaluate the effect of ERs on auditory sensitivity, ABR thresholds were measured before and 24 hours after acoustic trauma on WT and knockout mice (Figure 1). The knockout models included male and female ARKO, BERKO, and ERKO mice. One group of male and female WT mice are represented in each ABR panel together with the knockout mice. The mean auditory thresholds in WT mice before acoustic trauma were between 30 and $50 \mathrm{~dB}$ sound pressure level (SPL) across frequencies when measured between 12 and 22 weeks of age. Mean pre-trauma auditory thresholds from the knockout mice did not differ from the WT mice (data not shown), and no differences between males or females were found. These findings demonstrate that the deficiency of aromatase, ER $\alpha$, or ER $\beta$ has no direct effect on basal auditory sensitivity of mice 12-22 weeks of age. However, differences became apparent in ARKO and BERKO mice compared with WT and ERKO mice in ABR thresholds after an acoustic challenge. Acoustic challenge did not cause any sex-specific differences at any frequency among the different groups $\left(\mathrm{F}_{3,340}=0.044 ; P=0.988\right)$.

Male and female ARKO mice demonstrated a greater threshold shift (difference between pre-and post-trauma thresholds) after acoustic trauma compared with the WT mice. WT female mice showed a mean 12- to $25-\mathrm{dB}$ threshold shift across frequencies, while the ARKO females had greater threshold shifts (32-49 dB) (Figure 1). These differences were statistically significant at each frequency, as shown by using an all pairwise comparison $(8 \mathrm{kHz}$, $\mathrm{t}=5.52, P<0.001 ; 12.5 \mathrm{kHz}, \mathrm{t}=6.5, P<0.001 ; 16 \mathrm{kHz}, \mathrm{t}=7.2$, $P<0.001 ; 20 \mathrm{kHz}, \mathrm{t}=5.6, P<0.001)$. WT males had mean threshold shifts between 15 and $27 \mathrm{~dB}$ across frequencies, while the ARKO males showed significantly greater mean thresholds ranging between 33 and $50 \mathrm{~dB}$. These findings show that acoustic trauma affected the auditory system of ARKO male mice significantly more than WT male mice $(8 \mathrm{kHz}, \mathrm{t}=3.62, P<0.001 ; 12.5 \mathrm{kHz}$, $\mathrm{t}=3.43, P=0.001 ; 16 \mathrm{kHz}, \mathrm{t}=4.77, P<0.001 ; 20 \mathrm{kHz}, \mathrm{t}=4.96$, $P<0.001)$. No statistically significant differences were found between the ARKO males and females after acoustic challenge at any frequency $(8 \mathrm{kHz}, \mathrm{t}=0.176, P=0.87 ; 12.5 \mathrm{kHz}, \mathrm{t}=0.794$, $P=0.43 ; 16 \mathrm{kHz}, \mathrm{t}=0.794, P=0.43 ; 20 \mathrm{kHz}, \mathrm{t}=1.5, P=0.149)$.

The threshold shifts obtained from the BERKO females and males were significantly more elevated than in WT mice at all frequencies. Female BERKO mice showed mean threshold shifts between 32 and $45 \mathrm{~dB}$. These values differed from the female WT at all frequencies as shown by using an all pairwise comparison $(8 \mathrm{kHz}, \mathrm{t}=6.16, P<0.001 ; 12.5 \mathrm{kHz}, \mathrm{t}=5.76, P<0.001 ; 16 \mathrm{kHz}$, $\mathrm{t}=5.31, P<0.001 ; 20 \mathrm{kHz}, \mathrm{t}=4.9, P<0.001)$.

The ABR threshold shifts for the BERKO males ranged between 41 and $51 \mathrm{~dB}$ (Figure 1), and these threshold shifts were higher than the WT males for all frequencies measured $(8 \mathrm{kHz}, \mathrm{t}=4.34$, $P<0.001 ; 12.5 \mathrm{kHz}, \mathrm{t}=4.26, P<0.001 ; 16 \mathrm{kHz}, \mathrm{t}=3.13, P=0.002$; $20 \mathrm{kHz}, \mathrm{t}=3.65, P<0.001)$. Thus, BERKO male mice were significantly more affected by acoustic trauma than the WT male mice suggesting that $E R \beta$ can protect the auditory system. There was no significant difference between the BERKO males and females after acoustic challenge.

ERKO mice did not show any differences in ABR threshold shifts after acoustic trauma compared to WT mice, nor was any sex difference noted. The threshold shifts of the male and female ERKO mice were between 17 and $26 \mathrm{~dB}$ across frequencies (Figure 1), suggesting that the absence of ER $\alpha$ does not alter the response of the auditory system to acoustic trauma.

Effect of ER agonist treatment on auditory thresholds. In order to further characterize the role of $E R \alpha$ and $E R \beta$ on auditory function, we tested the potency of ER isoform specific agonists to protect against acoustic trauma (Figure 2). To address this issue, WT and ARKO female mice were treated with propyl $(1 \mathrm{H})$ pyrazole-1,3,5triyl-trisphenol (PPT; an ER $\alpha$ agonist) or 2,3-bis (4-hydroxyphenyl)propionitrile (DPN; an ER $\beta$ agonist) prior to acoustic trauma. Neither of these agonists altered pre-trauma auditory brainstem thresholds (data not shown).

PPT treatment followed by acoustic trauma did not alter auditory thresholds in WT mice compared with vehicle-treated WT mice. In contrast, DPN treatment protected auditory threshold shifts at all frequencies but was statistically significant at only $12.5 \mathrm{kHz}$ compared with vehicle-treated WT $(\mathrm{t}=3.34, P=0.004)$. When comparing the effects of PPT and DPN treatment on WT mice, protection against acoustic trauma was found only for DPN and at all frequencies $(8 \mathrm{kHz}, \mathrm{t}=3.92, P=0.002 ; 12.5 \mathrm{kHz}, \mathrm{t}=3.53$, $P=0.005 ; 16 \mathrm{kHz}, \mathrm{t}=2.75, P=0.034 ; 20 \mathrm{kHz}, \mathrm{t}=3.14, P=0.013)$.

ARKO mice treated with PPT showed threshold shifts that were 4-14 dB lower after acoustic trauma compared with untreated ARKO mice. The difference was statistically significant at 12.5 $\mathrm{kHz}(\mathrm{t}=2.51, P=0.021)$ and $16 \mathrm{kHz}(\mathrm{t}=2.35, P=0.03)$. When comparing the effects of DPN treatment on ARKO mice, mean threshold shifts were between 20 and $28 \mathrm{~dB}$, while vehicle-treated ARKO mice had mean threshold shifts between 33 and $49 \mathrm{~dB}$. ARKO mice were significantly protected against acoustic trauma 


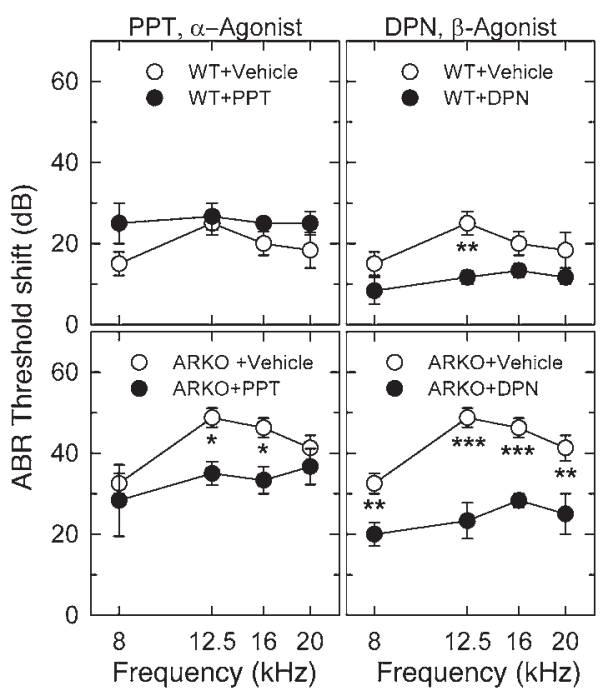

by pretreatment with DPN at all frequencies $(8 \mathrm{kHz}, \mathrm{t}=2.84$, $P=0.01 ; 12.5 \mathrm{kHz}, \mathrm{t}=5.77, P<0.001 ; 16 \mathrm{kHz}, \mathrm{t}=4.07, P<0.001$; $20 \mathrm{kHz}, \mathrm{t}=3.69, P=0.001)$.

The ARKO mice were protected against acoustic trauma after both PPT and DPN treatment. The protection was greater for treatment with DPN than with PPT $(\mathrm{t}=3.22, P=0.01)$ (Figure 2).

Localization and expression of ER $\beta$ in the cochlea. Immunocytochemistry was performed on WT male and female cochlea before and after acoustic trauma. ER $\beta$ was found in the nuclei of the inner and outer hair cells as well as the spiral ganglion nuclei (Figure 3). ER $\beta$ immunostaining was not found in the stria vascularis (Figure 3), spiral ligament, or any supporting cells. No obvious differences in the staining intensity or pattern were found between male and female mice, nor were changes found after acoustic trauma (data not shown). The staining pattern was further confirmed by the use of the different fixatives. Immunolabeling of $\operatorname{ER} \beta$ was significantly reduced in ARKO mice and absent in BERKO mice.

Protein extracts of cochlear homogenates collected from WT males and females were divided into cytosolic and nuclear fractions and analyzed for ER $\beta$ expression by western blot. This analysis showed equal ER $\beta$ expression in the nuclear fraction of cochlea from males and females (Figure 4). The cytosolic fraction from the cochlea did not demonstrate any ER $\beta$ expression.

\section{Figure 3}

Immunocytochemical localization of ER $\beta$ in the cochlea. Representative photomicrographs of cochlear sections (spiral ganglia neurons and stria vascularis) and surface preparations (hair cells) are shown. Strong immunoreactivity of ER $\beta$ was found in a selected population of spiral ganglion nuclei and in the nuclei of the inner and outer hair cells. More intense staining was found for the inner hair cell nuclei compared with the outer hair cells. Immunoreactivity was not found in the stria vascularis or the spiral ligament. The fixation was $4 \%$ paraformaldehyde in PBS.

\section{Figure 2}

Effects of agonist treatment on ABR thresholds $24 \mathrm{~h}$ after acoustic trauma. ABR threshold shifts $24 \mathrm{~h}$ after acoustic trauma in female WT and ARKO mice pretreated with either the ER $\alpha$ agonist (PPT), or the ER $\beta$ agonist (DPN). Control WT and ARKO mice were pretreated with saline. PPT treatment showed only partial protection at 12.5 and 16 $\mathrm{kHz}$ in ARKO mice. The amount of threshold shift was less for the DPNtreated mice compared with the vehicle-treated mice at $12.5 \mathrm{kHz}$ in WT and at all frequencies in ARKO mice. All data are mean \pm SEM, $n=3$ in each group. ${ }^{*} P<0.05$; ${ }^{* *} P<0.01$; ${ }^{* *} P<0.001$ by 2 -way ANOVA.

BDNF protein expression in the cochlea. The basal expression of BDNF protein in cochlea of WT mice was measured using ELISA. The concentration was $213 \pm 31 \mathrm{pg} / \mathrm{mg}$ in females and $202 \pm 28 \mathrm{pg} / \mathrm{mg}$ in males (Figure 5). The expression was significantly lower in BERKO females $(58 \pm 16 \mathrm{pg} / \mathrm{mg})$ and males $(68 \pm 8 \mathrm{pg} / \mathrm{mg})$. We then determined whether activity-dependent changes would occur after acoustic trauma. After acoustic trauma, changes of BDNF expression were found to be sex and strain dependent. After acoustic trauma, BERKO female mice showed no change in BDNF expression $(57 \pm 7 \mathrm{pg} / \mathrm{mg})$ in contrast to WT female mice, in which acoustic trauma resulted in a decrease in BDNF expression (105 $\pm 27 \mathrm{pg} / \mathrm{mg})$. BERKO male mice showed a slight decrease ( $40 \pm 2 \mathrm{pg} / \mathrm{mg})$ in BDNF protein expression after acoustic trauma, while in WT male mice a much larger decrease $(69 \pm 1 \mathrm{pg} / \mathrm{mg})$ was seen when measured immediately after acoustic trauma. The trauma-induced decrease in BDNF expression was more pronounced in WT mice of both sexes compared with BERKO mice (Figure 5).

ER $\beta$ agonist treatment affects BDNF in WT, ARKO, and ERKO mice. To further study the effect of ER $\beta$ agonist treatment in the cochlea, we determined the effect of DPN upon BDNF protein expression in cochlea of WT, ARKO, and ERKO female mice (Figure 6A). There was a main effect between strain and drug treatment on the BDNF protein expression $\left(\mathrm{F}_{2,12}=10.14, P=0.003\right)$.

The basal levels of BDNF in vehicle-treated WT $(238 \pm 16.04 \mathrm{pg} /$ $\mathrm{mg}$ protein) were close to that obtained from vehicle-untreated animals (see the previous paragraph). DPN treatment did not result in a change of BDNF protein expression in WT mice. Basal levels of BDNF in vehicle-treated ARKO mice were $12.6 \mathrm{pg} / \mathrm{mg}$ protein, which was significantly lower than in WT $(t=9.74$, $P<0.001)$. When ARKO mice were treated with DPN, the BDNF concentration increased to $77 \mathrm{pg} / \mathrm{mg}$ protein, which was statistically different from vehicle-treated ARKO mice $(t=2.79, P=0.016)$.

Estrogen Receptor $\beta$ Immunoreactivity in the Cochlea

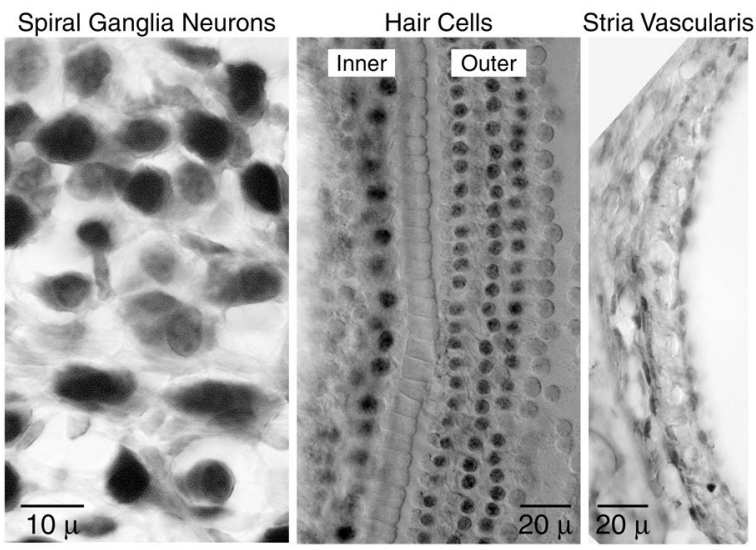




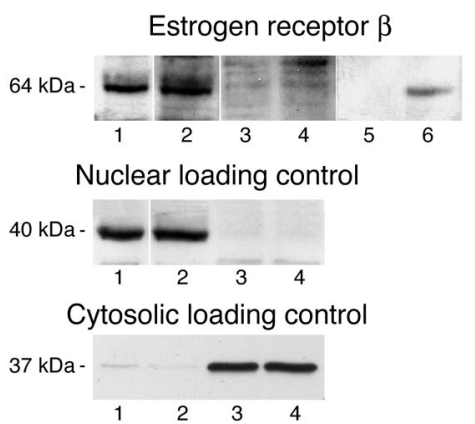

Figure 4

Representative western blot showing ER $\beta$ expression (upper panel) in the cochlea of WT males and females. Two independent experiments were performed with 5 mice (10 cochlea) in each group. Male (lane 1) and female (lane 2) nuclear fractions and male (lane 3) and female (lane 4) cytosolic fractions; $1 \mathrm{fmol}$ ER $\beta$-positive control (lane 5) and $20 \mathrm{fmol}$ of ER $\beta$-positive control (lane 6). Top row: ER $\beta$ was found in nuclear, but not in cytosolic, cochlear fractions of males and females. Middle row: Nuclear loading control using TATA-box binding protein. Bottom row: Cytosolic loading control using GAPDH.

The basal levels of BDNF in cochlea of vehicle-treated ERKO mice $(369.90 \pm 23.4 \mathrm{pg} / \mathrm{mg}$ protein) were significantly higher than in WT $(\mathrm{t}=5.68, P<0.001)$ or ARKO $(\mathrm{t}=15.42, P<0.001)$. BDNF concentration in ERKO mice was significantly upregulated after DPN treatment $(531.33 \pm 24.95 \mathrm{pg} / \mathrm{mg}$ protein) compared with ERKO vehicle-treated mice $(\mathrm{t}=6.97, P<0.001)$.

We evaluated the BDNF mRNA expression in cochlea of WT female mice after DPN treatment using real-time RT-PCR. BDNF mRNA expression level was low in vehicle-treated WT mice, and after DPN treatment there was an upregulation (10-fold) (Figure 6B), although changes on the protein level were not detected in this group. These findings demonstrate that DPN can upregulate BDNF expression in the cochlea of WT, ARKO, and ERKO mice.

\section{Discussion}

A ligand-dependent protective role for ER $\beta$ in the auditory system is demonstrated here for what we believe to be the first time. This protection against hearing loss was equally efficient in both male and female mice. The interesting features of this study were as follows: (a) BERKO and ARKO mice have increased susceptibility to acoustic trauma compared with WT and ERKO mice; (b) ER $\beta$ agonist treatment protects against trauma in WT and ARKO mice; (c) there is low BDNF expression in the cochlea of BERKO and ARKO mice compared with WT and ERKO mice; (d) there is an increase in BDNF protein following ER $\beta$ agonist treatment in ARKO and ERKO mice and in BDNF mRNA in WT mice. Taken together, these findings compellingly indicate a protective role of $E R \beta$ in the auditory system involving BDNF.

There is an extensive amount of knowledge on the effects of estradiol on the auditory system, but how each receptor subtype influences functional responses of the auditory system has not been previously studied. A loss or reduction of ER $\beta$ does not affect basal hearing thresholds or cochlear morphology in young BERKO or ARKO mice. Functional differences became apparent after an acoustic challenge in the BERKO and ARKO mice as demonstrated by exacerbated hearing thresholds. The finding that ER $\beta$ protects the auditory system against trauma is further substantiated by pharmacological treatment with PPT, a selective agonist for ER $\alpha$ subtype, or DPN, a selective ER $\beta$ agonist. DPN treatment protected against acoustic trauma in both WT and ARKO mice. In contrast, PPT treatment did not protect the WT and only partially protected the ARKO mice against trauma. A weak affinity of PPT to ER $\beta$ (31) has been found, suggesting that this cross-reactivity may play a role in PPT-treated ARKO mice. Taken together, the divergent ABR thresholds after acoustic trauma indicate that ER $\beta$ plays a more central role in modulating auditory sensitivity than ER $\alpha$.

The expression of ER $\beta$ was localized to the inner and outer hair cells, as well as the spiral ganglion neurons. These cells are important transducers of acoustic signals to the central nervous system. A sex-specific difference in the intensity of expression was not found. The pattern of immunostaining reported here differs from a previous report showing a more widespread immunostaining in the cochlea (32). That report showed staining in the inner hair cells and spiral ganglion neurons as well as in several nonneuronal cell populations, including the stria vascularis. The cause for these differences may be due to technical procedures (fixation or cochlear preparation) or the antibody employed. In the present study, several control experiments were performed that substantiated the pattern of ER $\beta$ staining in the cochlear tissues, such as the use of negative controls, including BERKO cochlea and blocking peptide, and the use of different fixation procedures and analysis by western blot with positive and negative controls. It is worthwhile to note that neither the immunostaining nor the western blot result showed gender-related differences in ER $\beta$ expression in young mice. The decreased labeling of ER $\beta$ in the ARKO mice may be a reflection of a low level of estrogens in this knockout mouse, resulting in a downregulation of ERs.

Increased ER $\beta$ expression is known to protect the central nervous system from a wide range of disorders, including amyloid toxicity (33), cerebral ischemia (34), and glutamate toxicity (35-38). The present study demonstrated that ER $\beta$-expressing mice (WT and ERKO) are more protected against acoustic trauma compared with ER $\beta$ knockouts and ARKO mice. Evidence exists showing that BDNF knockout mice have significant hearing loss, nerve loss, and hair cell loss compared with WT mice (28). Thus, we now have the possibility of protecting auditory function with $E R \beta$ agonists. Such pharmacological strategies have been proven effective in the auditory

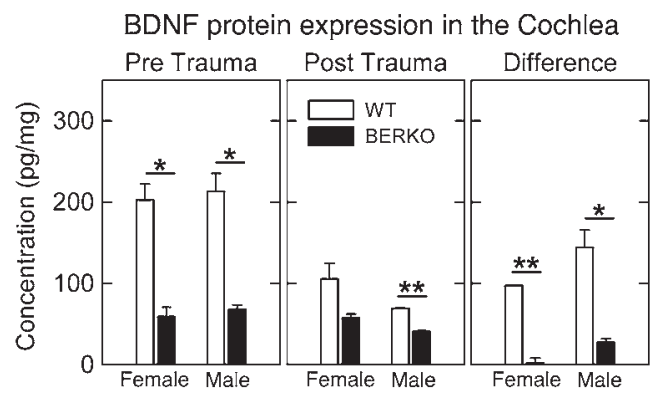

\section{Figure 5}

BDNF protein expression in WT and BERKO mice before and after acoustic trauma. Both male and female BERKO mice showed lower expression of basal BDNF compared with WT mice. Acoustic trauma decreased BDNF expression in both WT and BERKO mice. The differences between pre- and post-trauma concentration were greater in WT than in BERKO mice. Data are presented as a means \pm SEM, $n=3$ in each group. ${ }^{*} P<0.05$; ${ }^{* *} P<0.01$ by Student's $t$ test. 

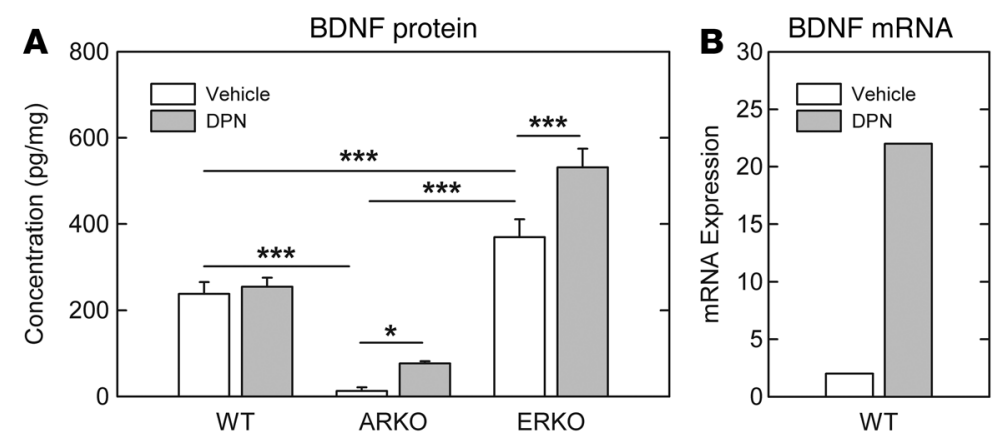

\section{Figure 6}

DPN affects BDNF expression. (A) BDNF protein expression in the cochlea of WT, ARKO, and ERKO mice injected with either vehicle (DMSO, open bars) or DPN (gray bars). DPN treatment increased BDNF protein in ARKO and ERKO mice. Values are means \pm SEM, $n=8$ cochlea in each group. ${ }^{*} P<0.05$; ${ }^{* *} P<0.001$ by 2 -way ANOVA. (B) BDNF mRNA expression in the cochlea of WT mice with or without DPN treatment. Each bar represents mRNA expression of 10 cochlea in $1 \mathrm{RT}-\mathrm{PCR}$ experiment. DPN treatment upregulated BDNF mRNA in the cochlea. system by using neurotrophins, such as BDNF and NT3 $(27,28)$, antioxidants (39-41), glutamate antagonists $(42,43)$, and, in the present study, ER $\beta$ agonists. In light of the ER effects reported here, BDNF is of particular interest due to its otoprotective properties that preserve hair cells and spiral ganglion neurons from degenerating after injury induced by ototoxic substances or acoustic trauma $(42,44)$. Moreover, an estrogen-sensitive response element is found on the BDNF gene, thus providing a further connection between estrogens and BDNF (29). BDNF is a peptide whose function in neuroprotection has recently been reviewed (45). We demonstrate here a functional relation between ER $\beta$ and BDNF in the cochlea, an interaction that has been reported previously in the brain (46). When basal levels of BDNF are relatively low, as in BERKO and ARKO mice, there is an increased susceptibility to acoustic trauma. Alternatively, when basal BDNF levels are relatively high, as in WT and ERKO mice with intact $\mathrm{ER} \beta$, the result is protection against acoustic trauma. Acoustic trauma decreased cochlear BDNF protein concentrations in WT and BERKO mice. This decrease can be the result of its release and subsequent degradation. In auditory neurons, one physiological role of BDNF is to mediate synaptic transmission and neural plasticity (47). Our findings show that WT mice degrade more BDNF during acoustic trauma compared with the BERKO mice, suggesting that this neurotrophin is released in an effort to protect auditory function.

The above-mentioned findings suggest that ER $\beta$ and BDNF concentrations influence auditory sensitivity when the system is challenged. Direct evidence for ER $\beta$-triggered upregulation of BDNF in the cochlea was revealed in experiments in which WT, ARKO, and ERKO mice were treated with DPN. The WT mice showed an increase in BDNF mRNA but not protein expression. The fact that BDNF protein in WT mice was not changed after DPN treatment, while BDNF mRNA was increased, may be due to a more complex $\mathrm{ER} \beta$ regulation of BDNF on a posttranscriptional level, or to ER $\beta$ affecting the mechanism of its release. The absence of a significant BDNF protein increase after DPN treatment in WT mice is partially reflected by the ABR threshold protection after trauma shown only at 1 frequency. ARKO mice showed a low level of BDNF protein expression compared with WT and a high susceptibility to acoustic trauma, yet after DPN treatment, BDNF protein levels increased and damage from acoustic trauma was reduced. ERKO mice have a functioning $\beta$ receptor and showed higher BDNF levels and less susceptibility to acoustic trauma. The sensitivity of the $\beta$ receptor in ERKO mice may be higher than in WT mice, since the ERKO mice have only 1 type of ER.

The molecular mechanisms concerning the overall neurotrophic and $\operatorname{ER} \beta$ protective effects remain to be determined. These effects appear to be primarily mediated through the activation of intracellular ERs, which results in the modulation of the transcription of estradiol target genes. The ability of estrogens to induce BDNF in selected brain regions is dependent on the level of progesterone and upon the time during which rodents are depleted of estrogens. Aromatase knockout mice can be considered to have long-term depletion of estrogens, and BERKO mice have low levels of progesterone because they rarely ovulate. These may be some reasons for their low BDNF concentration.

In summary, we have used a combination of animal models to investigate the functional and mechanistic role of ER $\beta$ in the auditory system. We present evidence that $\mathrm{ER} \beta$ protects the auditory system from acoustic trauma in young male and female mice. The findings support a model whereby $\mathrm{ER} \beta$ acts in concert with BDNF to promote neuronal plasticity and protection against trauma in the auditory system. Taken together, these pathways appear necessary for protecting the auditory system against trauma. The practical implications of this new information will help develop new therapeutic strategies against hearing loss.

\section{Methods}

Animals. A total of 149 mice of both sexes were used: WT, $n=70$ (29 males; 41 females); BERKO, $n=42$ (17 males; 25 females); ERKO, $n=12$; (6 males; 6 females); and ARKO, $n=29$ (4 males; 25 females) between 12 and 22 weeks of age. The homozygous mutant mice lacking the genes for ER $\beta$, $E R \alpha$, and aromatase, respectively, developed normally (48). BERKO and ERKO mice were generated as described in refs. 48 and 49, respectively, and were supplied by Taconic. ARKO mice were generated as previously reported (50) and bred at the animal facility at Huddinge hospital of the Karolinska Institute.

The animals were housed in groups of 5 animals per cage on an artificial 12-hour light/12-hour dark cycle (lights on at $7 \mathrm{am}$ ) with free access to food and water. The Ethical Committee at the Karolinska Institute approved the care and use of animals in this experiment.

Acoustic trauma. Animals were placed individually into small wire mesh cages $\left(10 \mathrm{~cm}^{3}\right)$ and then put inside an open-field acoustic chamber $(225 \times 120 \times 100$ $\mathrm{cm})$. During the exposure, the animals did not have any access to food or water. Free-field broadband noise at $6-12 \mathrm{kHz}$ was used for $45 \mathrm{~min}$ at intensity of $100 \mathrm{~dB}$ SPL. The stimulus was generated by a noise generator (Hewlett Packard; 33120 A), and delivered to the upper corners with 4 microphones. Calibration of the sound exposure levels was performed with a 12.5 - $\mathrm{mm}$ condenser microphone (Bruel and Kjaer; model 2213). The acoustic trauma used in this study caused a temporary change in auditory threshold shifts. This type of trauma does not lead to any morphological changes such as hair cell loss or degeneration of spiral ganglion neurons, and complete recovery of ABR thresholds occurs by $48 \mathrm{~h}(51)$.

Immunocytochemistry. Twenty-four hours after acoustic trauma, the animals were anesthetized, and a cardiac perfusion using $4 \%$ paraformaldehyde 
in PBS was performed prior to removing the cochlea. After fixation $(1 \mathrm{~h})$ the cochlea were decalcified using Rapid Decalcifying Agent (Apex Engineering Products Corporation) and then placed in $10 \%$ sucrose for $12-24 \mathrm{~h}$ at $4^{\circ} \mathrm{C}$, followed by $20 \%$ sucrose for $24 \mathrm{~h}$ for cryoprotection. Specimens were quickly deep frozen and stored at $-70^{\circ} \mathrm{C}$. Serial mid-modiolar sections (14 $\mu \mathrm{m}$ thickness) were cut on a cryostat (HM 500M; Zeiss) at $-24^{\circ} \mathrm{C}$. The sections were rinsed in PBS for 30 min before permeabilization with $0.3 \%$ Triton- $X$ in PBS, and then rinsed twice in PBS for 5 min each. Endogenous peroxidase was removed by using $3 \% \mathrm{H}_{2} \mathrm{O}_{2}$ in PBS for $30 \mathrm{~min}$. After rinsing twice in PBS for 5 min each, the slides were blocked with $1.5 \%$ goat serum in PBS for $30 \mathrm{~min}$. Then, polyclonal rabbit anti-ER $\beta$ antibody (catalog no. ab3577; Abcam) at a concentration of $5 \mu \mathrm{g} / \mathrm{ml}$ was used on the specimens overnight in a refrigerator. After several pilot studies, this concentration was found to be optimal for cochlear tissues. After rinsing twice in PBS, the secondary antibody, anti-rabbit IgG (Vector ABC kit) was added, followed by an immunoperoxidase reaction (VectaStain $\mathrm{ABC}$ kit and DAB substrate kit; Vector Laboratories). A negative control was treated in exactly the same way except without the use of primary antibody. Specificity of the antibody was tested by preincubation of the antibody with ER $\beta$-blocking peptide (catalog no. ab3564; Abcam) and application to cochlear sections, and as a negative control we used cochlear sections from BERKO mice. We also tested the effects of different fixatives on the staining pattern of ER $\beta$ in the cochlea. These different fixatives (4\% paraformaldehyde/ $1 \%$ acetic acid or $4 \%$ paraformaldehyde $/ 1 \%$ acetic acid/0.1\% glutaraldehyde) in PBS were compared with our standard fixation with $4 \%$ paraformaldehyde in PBS. Specificity of the antibody was further confirmed by western blot with positive controls (ER $\beta$ 530; Panvera).

Assessment of hearing function. ABR audiometry is a neurologic test of auditory brainstem function in response to auditory stimuli. ABR audiometry is an evoked potential measured by surface electrodes, where the signal is averaged and plotted against time (milliseconds). The ABR provides information regarding auditory function and hearing sensitivity. Auditory sensitivity was assessed with ABR thresholds for the frequency of 8, 12.5,16, and $20 \mathrm{kHz}$ after the mice were anesthetized with an intraperitoneal injection of ketamine $(50 \mathrm{mg} / \mathrm{kg})$ and xylazine $(10 \mathrm{mg} / \mathrm{kg})$. The body temperature of the animals was maintained at $38.0^{\circ} \mathrm{C}$ using light heating and cotton coverings. ABR thresholds were recorded with subcutaneously inserted stainless steel electrodes as the potential difference between an electrode on the vertex and an electrode on the mastoid, while the lower back served as ground, as previously described (52). The stimuli were generated through Tucker-Davis Technologies equipment controlled by computer and delivered by EC1 speakers for closed-field stimulation (Tucker-Davis Technologies). The acoustic signal was delivered through the system, inserted into the external auditory meatus, and presented at a repetition rate of 20 repetitions/second. The stimuli consisted of full-cycle sine waves at $8,12.5$, 16 , and $20 \mathrm{kHz}$. The duration of the sine waves varied with the frequency but always had the same number of cycles. The acoustic stimuli were synthesized digitally by using SigGen software (Tucker Davis Technologies), passed through an anti-aliasing filter with a low-pass cutoff of $25 \mathrm{kHz}$, input into a programmable attenuator (Tucker Davis Technologies; PA-4) and then through a headphone buffer (Tucker Davis Technologies; HB1), and transduced by an earphone (Telephonics; TDH 39). The stimuli were delivered into the external auditory meatus through a closed acoustic system. The acoustic system was calibrated for each frequency using a Bruel and Kjaer measuring amplifier (type 2610). A Bruel and Kjaer 4230 (94 dB $\mathrm{SPL}$ ) piston phone at $1,000 \mathrm{~Hz}$ was used as a reference. Stimulus intensity was calibrated in a $0.5 \mathrm{~cm}^{3}$ coupler with a one-quarter-inch condenser microphone (Bruel and Kjaer; 4135) at the end of the plastic tubing, close to the tympanic membrane. The root mean square level of the pure tone was used for calibration. Potentials were amplified by a differential AC amplifier (BioAmp; Axon Instruments) with a gain of 100,000 and filters that were set between $10 \mathrm{~Hz}$ and $3 \mathrm{kHz}$. The rejection rate of these filters was $-6 \mathrm{~dB} /$ octave. Each response was digitized via a 16-bit analog-to-digital converter (Tucker Davis Technologies) with a sampling rate of $50 \mathrm{kHz}$ and a sampling window of $25 \mathrm{~ms}$. The potentials were processed with BioSig software (Tucker Davis Technologies) and averaged 1,000 sweeps in realtime using a digital signal processor with a time-domain artifact rejection. Stimuli were presented at an intensity well above threshold and then decreased in 10-dB steps until the threshold was approached, and then in $5-\mathrm{dB}$ steps until the ABR wave disappeared. Threshold was defined as the lowest intensity at which a visible ABR wave was seen in 2 averaged runs.

Pharmacological treatment. PPT (catalog no. 1426), a selective agonist for ER $\alpha$, and DPN (catalog no. 1494), a selective ER $\beta$ agonist, were purchased from TOCRIS Cookson and dissolved in DMSO (1\%), injected daily at a dose of $1 \mathrm{mg} / \mathrm{kg}$ for 1 week. Control animals were treated with DMSO.

Tissue preparation. After measuring ABR, deeply anesthetized animals were transcardially perfused with $200 \mathrm{ml}$ of $0.1 \mathrm{M}$ phosphate buffer, $\mathrm{pH} 7.4$ (PBS) containing heparin $10 \mathrm{IU} / \mathrm{ml}$, followed by $200 \mathrm{ml}$ of $4 \%$ paraformaldehyde in PBS. Each cochlea was removed and placed in $4 \%$ paraformaldehyde at $4{ }^{\circ} \mathrm{C}$ for further fixation. For preparing the cochlear whole mount, the bone surrounding the organ of Corti was dissected free and the tectorial membrane was removed. For the cross-section preparation, the cochlea was decalcified using Rapid Decalcifying Agent (Apex Engineering Products Corporation). The cochlea was put in graded sucrose/PBS and then processed for fixation and cryostat sectioning (14- $\mu \mathrm{m}$-thick sections). Cochlear surface preparations were made as previously described (53).

Tissue collection and protein isolation. Mice were sacrificed by cardiac perfusion with ice-cold PBS with heparin, and cochlea were immediately removed and placed into ice-cold solution containing Complete protease inhibitor (Roche Diagnostics), $1 \mathrm{mM}$ DTT, and $1 \mathrm{mM} \mathrm{Na}_{3} \mathrm{VO}_{4}$. Cochlea were perfused through the round window, and the bony shell was removed. Collected tissue was preserved at $-70^{\circ} \mathrm{C}$. To obtain a total protein extract, cochlea of 3 mice were pooled. Tissue was lysed for $40 \mathrm{~min}$ on ice in lysis buffer containing (in $\mathrm{mM}$ ): 20 Tris- $\mathrm{HCl}$ (pH 7.0), 1 EDTA, 1 EGTA, 150 $\mathrm{NaCl}, 2.5$ sodium pyrophosphate, 1 sodium glycerophosphate, 1 DTT, $1 \mathrm{Na}_{3} \mathrm{VO}_{4}, 1 \% \mathrm{vol} / \mathrm{vol}$ Triton X-100, and complete protease inhibitor (Roche Diagnostics). The mixture was centrifuged at $15,000 \mathrm{~g}$ for $5 \mathrm{~min}$ at $4^{\circ} \mathrm{C}$ to give lysates. All lysates were frozen and stored at $-80^{\circ} \mathrm{C}$ until assayed. Protein concentration in lysates was determined according to Bradford method (54), using bovine serum albumin as a standard. To separate cytosolic and nuclear fractions, the cochlea were pooled and placed in lysis buffer containing $25 \mathrm{mM}$ Tris ( $\mathrm{pH} 7.5$ ), $50 \mathrm{mM} \mathrm{KCl}, 2 \mathrm{mM} \mathrm{MgCl}, 1 \mathrm{mM}$ EDTA, 1 DTT, and complete protease inhibitor. The tissue was homogenized on ice and centrifuged at $1700 \mathrm{~g}$ for $10 \mathrm{~min}$ at $4^{\circ} \mathrm{C}$, and supernatant was collected for the cytosolic fraction. The precipitate was resuspended in a new buffer (25 mM Tris [pH 7.5], $0.42 \mathrm{M} \mathrm{NaCl}, 1.5 \mathrm{mM} \mathrm{MgCl}_{2}, 0.5 \mathrm{mM}$ EDTA, $25 \%$ sucrose, DTT, and complete protease inhibitor), lysed for $40 \mathrm{~min}$ on ice, and centrifuged at $20,000 \mathrm{~g}$ for $30 \mathrm{~min}$ at $4^{\circ} \mathrm{C}$, and supernatant was collected as the nuclear fraction. Both cytosolic and nuclear fractions were concentrated using the PAGE Prep Advance Kit (catalog no. 89888; Pierce Biotechnology). The concentration of protein was measured using BSA Protein Assay Kit (catalog no. 23227; Pierce Biotechnology).

BDNF immunoassay. BDNF concentration was evaluated using the BDNF $\mathrm{E}_{\max }$ ImmunoAssay System (catalog no. G7610; Promega Corp.). The lowest detectable concentration was $16 \mathrm{pg} / \mathrm{ml}$, and the cross-reactivity with other related neurotrophins was less than $3 \%$ at $100 \mathrm{ng} / \mathrm{ml}$. The proteins extracted as described above were analyzed according to the manufacturer's protocol. The data are presented as pg of BDNF for $1 \mathrm{mg}$ of total protein.

Western blot analysis. Concentrated nuclear or cytosolic protein fractions containing $28 \mu \mathrm{g}$ total protein per sample were resuspended in NuPAGE 
LDS Sample Buffer (catalog no. NP0007; Invitrogen) supplemented with DTT, heated for $5 \mathrm{~min}$ at $95^{\circ} \mathrm{C}$, and separated by SDS-PAGE electrophoresis (55) using a $4 \%$ spacer and a $12 \%$ (wt/vol) separating polyacrylamide gel. Proteins were transferred to a PVDF membrane (Amersham Pharmacia Biotech) by semi-dry electroblotting. For detection, PVDF membranes were blocked for $2 \mathrm{~h}$ in TBST (TBS, $20 \mathrm{mM}$ Tris, $150 \mathrm{mM} \mathrm{NaCl}$, pH 7.6, containing $0.1 \%$ [vol/vol] Tween-20) supplemented with $5 \%$ non-fat dry milk prior to overnight incubation with the primary antibodies. After three 10-min washing steps using TBST, the PVDF membranes were incubated for $1 \mathrm{~h}$ with peroxidase-conjugated anti-rabbit or anti-mouse IgG goat antibodies (Pierce Biotechnology). Thereafter, the PVDF membranes were washed 3 times for $10 \mathrm{~min}$ and 2 times for $1 \mathrm{~min}$ with TBST or TBS, respectively, to remove residual antibody. The PVDF membranes were developed with an enhanced chemiluminescence western blot detection kit (Pierce SuperSignal West Dura) and exposed to Lumi-Film chemiluminescent detection films (Roche Diagnostics) for 5, 10, 15, and $20 \mathrm{~min}$ for anti-ER $\beta$. The nuclear protein fraction was verified by TATA-box binding protein (TBP) expression as a nuclear loading control, and cytosolic fraction was verified by GAPDH expression as a cytosolic loading control.

Antibodies used for western blot were anti-ER $\beta$ rabbit polyclonal (developed at Department of BioSciences and Nutrition, Novum, Karolinska Institutet), anti-TBP mouse monoclonal (dilution 1/1000, catalog no. ab818; Abcam Ltd.), and anti-GAPDH rabbit polyclonal (dilution 1/1000, catalog no. ab9484; Abcam Ltd.). The specificity of anti-ER $\beta$ antibody was verified by using positive controls (ER $\beta$ 530; Panvera), and tissue from BERKO cochlea was used as a negative control.

$R N A$ isolation and real-time quantitative RT-PCR. Mice were killed by cranial dislocation, cochlea immediately removed, placed into the ice-cold RNAlater solution (Qiagen). The cochlea part was dissected from the temporal bone and frozen at $-70^{\circ} \mathrm{C}$ for further analysis. Total RNA was extracted from 2 cochlea of each individual mouse using RNeasy Mini kit (Qiagen) according to the manufacturer's instructions. The concentration of yielded RNA was assessed by spectrophotometry (SmartSpeck Plus; BioRad) at $260 \mathrm{~nm}$ (conversion factor 40). The RNA quality was evaluated with $0.9 \%$ agarose gel electrophoresis. RNA samples were aliquoted and stored at $-70^{\circ} \mathrm{C}$.

cDNA was generated from total RNA by reverse transcription with random primers (Invitrogen) and reverse transcriptase Superscript III RT
(Invitrogen). For quantitative determination of BDNF expression, quantitative real-time PCR was performed (Applied Biosystems). BDNF mRNA expression was assessed using specific primers and SYBR Green Master Mix (Applied Biosystems).

PCR primers were as follows. For BDNF (M61175): forward, 5'-GTCCACGGACAAGGCAACTTGG-3', and reverse, 5'-ACCGGACATGTCCACTGCAGTC-3'; for $18 \mathrm{~S}$ (used as an internal control): forward, 5'-CCTGCGGCTTAATTTGACTCA-3' , and reverse, 5'-AGCTATCAATCTGTCAATCCTGTCC-3'.

Statistics. Data are presented as means \pm SEM. The comparisons of the means were performed for comparison of 2 groups with a Student's unpaired 2-tailed $t$ test and for multiple comparisons with 2-way ANOVA with Bonferroni ad-hoc correction. The software SigmaStat version 2.03 (Systat Inc.) was used for statistical analysis.

\section{Acknowledgments}

The authors wish to thank Margaret Warner for helpful discussions on the experimental design of this study and Agneta Viberg for excellent technical assistance. B. Canlon is supported from the Swedish Research Council, Center for Gender Medicine, Karolinska Institutet, Funds of Karolinska Institute, AMF Trygghetsförsäkring, Tysta Skolan, and Loo and Hans Östermans Fund. J.-Å. Gustafsson is supported by grants from the Swedish Cancer Society, KaroBio AB, the EU-FP6-project EWA, LSHM-CT2005-518245. E. Simpson is supported by NHMRC Project Grant 169010 and NHMRC Program Grant 24100. The agencies who have supported this study were not involved in the design, interpretation, analysis, or review of the data.

Received for publication May 24, 2007, and accepted in revised form January 9, 2008.

Address correspondence to: Barbara Canlon, Karolinska Institute, Von Eulers vagen 8, Department of Physiology and Pharmacology, Stockholm 17177, Sweden. Phone: 46-8-524-872-48; Fax: 468-327026; E-mail: Barbara.Canlon@ki.se.

Inna Meltser and Yeasmin Tahera contributed equally to this work.
1. Haggard, M., and Gaston, J.B. 1978. Changes in auditory perception in the menstrual cycle. $\mathrm{Br}$. J. Audiol. 12:105-118.

2. Jerger, J., and Johnson, K. 1988. Interactions of age, gender, and sensorineural hearing loss on ABR latency. Ear Hear. 9:168-176.

3. Wharton, J.A., and Church, G.T. 1990. Influence of menopause on the auditory brainstem response. Audiology. 29:196-201.

4. Coleman, J.R., Campbell, D., Cooper, W.A., Welsh, M.G., and Moyer, J. 1994. Auditory brainstem responses after ovariectomy and estrogen replacement in rat. Hear. Res. 80:209-215.

5. McFadden, D. 1993. A masculinizing effect on the auditory systems of human females having male cotwins. Proc. Natl. Acad. Sci. U. S. A. 90:11900-11904.

6. McFadden, D. 2000. Masculinizing effects on otoacoustic emissions and auditory evoked potentials in women using oral contraceptives. Hear. Res. 142:23-33.

7. McFadden, D., and Pasanen, E.G. 1999. Spontaneous otoacoustic emissions in heterosexuals, homosexuals, and bisexuals. J. Acoust. Soc. Am. 105:2403-2413.

8. McFadden, D., Pasanen, E.G., and Callaway, N.L. 1998. Changes in otoacoustic emissions in a transsexual male during treatment with estrogen. J. Acoust. Soc. Am. 104:1555-1558.
9. Sisneros, J.A., Forlano, P.M., Deitcher, D.L., and Bass, A.H. 2004. Steroid-dependent auditory plasticity leads to adaptive coupling of sender and receiver. Science. 305:404-407.

10. Hultcrantz, M., Stenberg, A.E., Fransson, A., and Canlon, B. 2000. Characterization of hearing in an X,0 'Turner mouse'. Hear. Res. 143:182-188.

11. Dorrington, J.H., Fritz, I.B., and Armstrong, D.T. 1978. Control of testicular estrogen synthesis. Biol. Reprod. 18:55-64.

12. Dupont, S., et al. 2000. Effect of single and compound knockouts of estrogen receptors alpha (ERalpha) and beta (ERbeta) on mouse reproductive phenotypes. Development. 127:4277-4291.

13. Eddy, E.M., et al. 1996. Targeted disruption of the estrogen receptor gene in male mice causes alteration of spermatogenesis and infertility. Endocrinology. 137:4796-4805.

14. Levallet, J., et al. 1998. Expression and immunolocalization of functional cytochrome P450 aromatase in mature rat testicular cells. Biol. Reprod. 58:919-926.

15. Makela, S., et al. 2000. Differential expression of estrogen receptors alpha and beta in adult rat accessory sex glands and lower urinary tract. Mol. Cell. Endocrinol. 164:109-116.

16. Carreau, S. 2003. Estrogens - male hormones?
Folia Histochem. Cytobiol. 41:107-111.

17. Kimura, M., et al. 2003. Impaired acetylcholineinduced release of nitric oxide in the aorta of male aromatase-knockout mice: regulation of nitric oxide production by endogenous sex hormones in males. Circ. Res. 93:1267-1271.

18. Bialek, M., Zaremba, P., Borowicz, K.K., and Czuczwar, S.J. 2004. Neuroprotective role of testosterone in the nervous system. Pol. J. Pharmacol. 56:509-518.

19. MacLusky, N.J., Philip, A., Hurlburt, C., and Naftolin, F. 1985. Estrogen formation in the developing rat brain: sex differences in aromatase activity during early post-natal life. Psychoneuroendocrinology. 10:355-361.

20. Green, S., et al. 1986. Cloning of the human oestrogen receptor cDNA. J. Steroid Biochem. 24:77-83.

21. Kuiper, G.G., Enmark, E., Pelto-Huikko, M., Nilsson, S., and Gustafsson, J.A. 1996. Cloning of a novel receptor expressed in rat prostate and ovary. Proc. Natl. Acad. Sci. U. S. A. 93:5925-5930.

22. Paech, K., et al. 1997. Differential ligand activation of estrogen receptors ERalpha and ERbeta at AP1 sites. Science. 277:1508-1510.

23. Matthews, J., and Gustafsson, J.A. 2003. Estrogen signaling: a subtle balance between ER alpha and ER beta. Mol. Interv. 3:281-292.

24. Couse, J.F., Lindzey, J., Grandien, K., Gustafs- 
son, J.A., and Korach, K.S. 1997. Tissue distribution and quantitative analysis of estrogen receptor-alpha (ERalpha) and estrogen receptor-beta (ERbeta) messenger ribonucleic acid in the wildtype and ERalpha-knockout mouse. Endocrinology. 138:4613-4621.

25. Kuiper, G.G., et al. 1997. Comparison of the ligand binding specificity and transcript tissue distribution of estrogen receptors alpha and beta. Endocrinology. 138:863-870.

26. Nilsson, S., and Gustafsson, J.A. 2000. Estrogen receptor transcription and transactivation: Basic aspects of estrogen action. Breast Cancer Res. 2:360-366

27. Staecker, H., Gabaizadeh, R., Federoff, H., and Van De Water, T.R. 1998. Brain-derived neurotrophic factor gene therapy prevents spiral ganglion degeneration after hair cell loss. Otolaryngol. Head Neck Surg. 119:7-13.

28. Agerman, K., et al. 2003. BDNF gene replacement reveals multiple mechanisms for establishing neurotrophin specificity during sensory nervous system development. Development. 130:1479-1491.

29. Sohrabji, F., Miranda, R.C., and Toran-Allerand, C.D. 1995. Identification of a putative estrogen response element in the gene encoding brainderived neurotrophic factor. Proc. Natl. Acad. Sci. U. S. A. 92:11110-11114.

30. Toran-Allerand, C.D., et al. 1992. Estrogen receptors colocalize with low-affinity nerve growth factor receptors in cholinergic neurons of the basal forebrain. Proc. Natl. Acad. Sci. U. S. A. 89:4668-4672

31. Stauffer, S.R., et al. 2000. Pyrazole ligands: structure-affinity/activity relationships and estrogen receptor-alpha-selective agonists. J. Med. Chem. 43:4934-4947.

32. Stenberg, A.E., et al. 2001. Estrogen receptors in the normal adult and developing human inner ear and in Turner's syndrome. Hear. Res. 157:87-92.

33. Fitzpatrick, J.L., et al. 2002. Estrogen-mediated neuroprotection against beta-amyloid toxicity requires expression of estrogen receptor alpha or beta and activation of the MAPK pathway. J. Neuro- chem. 82:674-682.

34. Miller, N.R., Jover, T., Cohen, H.W., Zukin, R.S., and Etgen, A.M. 2005. Estrogen can act via estrogen receptor alpha and beta to protect hippocampa neurons against global ischemia-induced cell death. Endocrinology. 146:3070-3079.

35. Bae, Y.H., Hwang, J.Y., Kim, Y.H., and Koh, J.Y. 2000. Anti-oxidative neuroprotection by estrogens in mouse cortical cultures. J. Korean Med. Sci. 15:327-336.

36. Bakker, J., Honda, S., Harada, N., and Balthazart, J. 2003. The aromatase knockout (ArKO) mouse provides new evidence that estrogens are required for the development of the female brain. Ann. N. Y. Acad. Sci. 1007:251-262.

37. Mize, A.L., Shapiro, R.A., and Dorsa, D.M. 2003. Estrogen receptor-mediated neuroprotection from oxidative stress requires activation of the mitogenactivated protein kinase pathway. Endocrinology. 144:306-312.

38. Zhao, L., Wu, T.W., and Brinton, R.D. 2004. Estrogen receptor subtypes alpha and beta contribute to neuroprotection and increased $\mathrm{Bcl}-2$ expression in primary hippocampal neurons. Brain Res. 1010:22-34.

39. Canlon, B., et al. 2003. Alterations in the intrauterine environment by glucocorticoids modifies the developmental programme of the auditory system. Eur. J. Neurosci. 17:2035-2041.

40. Harris, K.C., Bielefeld, E., Hu, B.H., and Henderson, D. 2006. Increased resistance to free radical damage induced by low-level sound conditioning. Hear. Res. 213:118-129.

41. Seidman, M.D., Shivapuja, B.G., and Quirk, W.S 1993. The protective effects of allopurinol and superoxide dismutase on noise-induced cochlear damage. Otolaryngol. Head Neck Surg. 109:1052-1056.

42. Duan, M., Agerman, K., Ernfors, P., and Canlon, B. 2000. Complementary roles of neurotrophin 3 and a $\mathrm{N}$-methyl-D-aspartate antagonist in the protection of noise and aminoglycoside-induced ototoxicity. Proc. Natl. Acad. Sci. U. S. A. 97:7597-7602.

43. Pujol, R. 1994. Lateral and medial efferents: a double neurochemical mechanism to protect and regulate inner and outer hair cell function in the cochlea. Br. J. Audiol. 28:185-191.

44. Ernfors, P., Duan, M.L., ElShamy, W.M., and Canlon, B. 1996. Protection of auditory neurons from aminoglycoside toxicity by neurotrophin-3. Nat. Med. 2:463-467.

45. Sohrabji, F., and Lewis, D.K. 2006. Estrogen-BDNF interactions: implications for neurodegenerative diseases. Front. Neuroendocrinol. 27:404-414.

46. Blurton-Jones, M., Kuan, P.N., and Tuszynski, M.H. 2004. Anatomical evidence for transsynaptic influences of estrogen on brain-derived neurotrophic factor expression. J. Comp. Neurol. 468:347-360.

47. Ruttiger, L., et al. 2006. BDNF mRNA expression and protein localization are changed in age-related hearing loss. Neurobiol. Aging. 28:586-601.

48. Krege, J.H., et al. 1998. Generation and reproductive phenotypes of mice lacking estrogen receptor beta. Proc. Natl. Acad. Sci. U. S. A. 95:15677-15682.

49. Das, S.K., et al. 1997. Estrogenic responses in estrogen receptor-alpha deficient mice reveal a distinct estrogen signaling pathway. Proc. Natl. Acad. Sci. U. S. A. 94:12786-12791.

50. Fisher, C.R., Graves, K.H., Parlow, A.F., and Simpson, E.R. 1998. Characterization of mice deficient in aromatase $(\mathrm{ArKO})$ because of targeted disruption of the cyp19 gene. Proc. Natl. Acad. Sci. U. S. A. 95:6965-6970.

51. Tahera, Y., et al. 2006. NF-kappaB mediated glucocorticoid response in the inner ear after acoustic trauma. J. Neurosci. Res. 83:1066-1076.

52. Niu, X., Tahera, Y., and Canlon, B. 2004. Protection against acoustic trauma by forward and backward sound conditioning. Audiol. Neurootol. 9:265-273.

53. Viberg, A., and Canlon, B. 2004. The guide to plotting a cochleogram. Hear. Res. 197:1-10.

54. Bradford, M.M. 1976. A rapid and sensitive method for the quantitation of microgram quantities of protein utilizing the principle of protein-dye binding. Anal. Biochem. 72:248-254.

55. Laemmli, U.K. 1970. Cleavage of structural proteins during the assembly of the head of bacteriophage T4. Nature. 227:680-685. 